\title{
ESCENA
}

Publicación semestral. ISSN 2215-4906

Volumen 80 - Número 1

Julio - Diciembre 2020

\section{La mirada gay y el cuerpo masculino en la fotografía homoerótica}

\author{
The Gay Male Gaze and the Male Body on Homoerotic \\ Photography
}

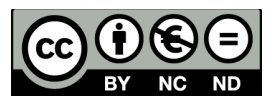

Esta obra está bajo una licencia Creative Commons Reconocimiento-No comercial-Sin Obra Derivada 


\title{
La mirada gay y el cuerpo masculino en la fotografía homoerótica
}

\author{
The Gay Male Gaze and the Male Body on Homoerotic \\ Photography
}

\author{
César Rivera Ávila ${ }^{1}$ \\ Universidad de Costa Rica \\ Costa Rica
}

Recibido: 17 de octubre de 2019 Aprobado: 04 de marzo de 2020

\begin{abstract}
Resumen
Tradicionalmente, la mujer ha sido el objeto de la fotografía erótica dirigida a un público heterosexual masculino. Sin embargo, en la fotografía gay homoerótica, tanto el público meta como el sujeto fotografiado están constituidos por hombres homosexuales. La primera sección de este artículo aborda el desnudo en el arte; la siguiente, trata sobre la fotografía homoerótica y la última analiza la mirada gay y la manera en que el cuerpo masculino es moldeado y representado en la fotografía homoerótica.
\end{abstract}

Palabras clave: fotografía; homoerotismo; mirada; desnudo; cuerpo

\begin{abstract}
Typically, women have been the object of the erotic photography, aimed to a heterosexual male public, however, on gay homoerotic photography, both the target audience and the photographed subject, are homosexual men. The first section of this article addresses the nude in art; the following, deals with homoerotic photography, while the last section analyzes the gay male gaze and the way the male body is shaped and represented on homoerotic photography.
\end{abstract}

Keywords: photography; homoerotism; gaze; nude; body

1 Estudiante de la Licenciatura en Historia en la Universidad de Costa Rica. ORCID: 0000-0003-30611614. Correo electrónico: cesrivera17@gmail.com

ESCENA. Revista de las artes, 2020, Vol. 80, Núm. 1, pp. 223-232 ISSN 2215-4906 


\section{Introducción}

El problema de la mirada masculina ha sido abordado, tradicionalmente, desde la colocación de la mujer como objeto pasivo de la mirada del hombre (Mulvey, 1999, pp. 837838). De ese modo, la mujer es vista como portadora de significado y no como creadora, pues este es el papel que asumen los hombres; a la vez, se limita su capacidad para ejercer poder u obtener placer desde el ámbito del consumo visual. Sin embargo, este marco analítico no resulta pertinente a la hora de analizar la mirada que se dirige desde el hombre hacia otros varones. Entonces, ¿qué ocurre cuando lo masculino no es solo quien dirige la mirada, sino también el objeto de esta? El presente ensayo pretende, precisamente, responder a la interrogante de cómo se representa el cuerpo masculino desde la mirada gay (gay male gaze) en la fotografía homoerótica.

\section{El desnudo en el arte}

Existen múltiples maneras de aproximarse al tema de la desnudez. Si bien puede ser entendida únicamente como la ausencia de vestido sobre el cuerpo, varios autores, entre ellos Giorgio Agamben, han ahondado en el asunto. Para este autor, la desnudez no es un mero estado ya dado, sino un acontecimiento: se expresa mediante el despojo de vestido, es decir, es siempre desnudamiento y nunca una forma estable; por tanto, únicamente habría personas desnudadas, pero no desnudas (Agamben, 2011).

En lo que respecta al arte, es necesario distinguir entre el desnudo corporal (carencia de vestimenta), que puede ser fuente de vergüenza o humillación según las circunstancias, y el desnudo artístico (the nude), que no acumula las cargas negativas antes mencionadas y que, más bien, refleja confianza y empoderamiento del cuerpo que lo exhibe (Clark, 1984). De ese modo, a pesar de que, en muchas culturas alrededor del mundo y a lo largo del tiempo, se han representado cuerpos desnudos, no todos serían considerados desnudos artísticos. Para Clark (1984), este tipo de desnudo debe despertar, aunque sea, un mínimo vestigio de sentimiento erótico en el espectador: debe ser parte de la intención de la obra, en donde el cuerpo desvestido sea el tema central.

Ya en el siglo XVI, la búsqueda de las proporciones ideales del cuerpo humano era una preocupación central en la obra y en los tratados de artistas, como lo demuestran, por ejemplo, los distintos hombres vitruvianos (el más famoso es el de Leonardo da Vinci), en donde una persona con sus extremidades extendidas encajaba sin problemas dentro de las figuras consideradas perfectas, es decir, en el cuadrado y el círculo (Clark, 1984). Aún en la sociedad occidental contemporánea, los estrictos estándares de belleza son indicadores de la creencia en un cuerpo ideal. Cuando se emite un juicio estético sobre el cuerpo de una 
persona -senos muy pequeños, torso poco tonificado, baja estatura, caderas muy anchas-, está implícita la idea de que existe una belleza ideal (Clark, 1984).

Con la invención del daguerrotipo, en 1839, y con su posterior evolución y difusión, surge también una nueva manera de aproximarse a las imágenes, una nueva mirada. Tal y como lo indica Susan Sontag, en efecto, "las fotografías alteran y amplían nuestras nociones de lo que merece la pena mirar y de lo que tenemos derecho a observar" (Sontag, 2007, p. 6); los objetos dignos de nuestra mirada y nuestra atención, entonces, se multiplicaron. De esa manera, se desarrollan nuevas vías de representar el cuerpo humano que, aunque al principio se interpretan como objetivas ${ }^{2}$, no dejan de ser, al igual que la pintura, el dibujo y la escultura, interpretaciones del mundo, mediadas por la subjetividad de quien toma la fotografía. Toda representación gráfica, en consecuencia, nos habla sobre sus creadores y de su audiencia, así como del contexto sociohistórico en que fueron producidas.

Con la cámara fotográfica también se manifiestan otras maneras de interactuar frente a los cuerpos: tomar o poseer una fotografía permite apropiarse de manera simbólica del objeto fotografiado. Sontag (2007) incluso llega a afirmar que "fotografiar personas es violarlas... es cometer un asesinato sublimado" (p. 31), puesto que convierte a estas personas en objetos que pueden ser poseídos físicamente -la impresión de la fotografía- y simbólicamente. Asimismo, a lo largo de la historia, han sido utilizadas como manera de control social -cédulas de identidad, registros fotográficos policiales, clínicos, entre otros-, como bien lo indican sociólogos y filósofos ${ }^{3}$.

Existen fotografías de carácter erótico desde la segunda mitad del siglo XIX, sin embargo, los fotógrafos se veían obligados a actuar en la clandestinidad y el anonimato para escapar de la censura, de los problemas con la justicia y de la cárcel. Según Dupouy (2015), las primeras décadas de la fotografía erótica fueron esencialmente francesas, debido a que fue Francia el país en donde se desarrolló en principio la fotografía, y donde la sociedad era más liberal en comparación con la de sus vecinos. Imágenes de desnudos femeninos fueron enviadas desde Francia a Italia, España, Alemania, Estados Unidos, entre otros países, debido a que allí la producción de estas era severamente reprimida.

2 La cámara puede reproducir la imagen del objeto tal y como este es, por lo que podía representar gráficamente "la verdad".

3 Un ejemplo de esto es el uso dado por la policía parisina, durante la redada de los communards, en junio del año 1871, en donde se utilizó la fotografía como manera de identificar a los involucrados en la Comuna de París, para luego perseguirlos. (Sontag, 2007, 18).

ESCENA. Revista de las artes, 2020, Vol. 80, Núm. 1 (julio-diciembre), pp. 223-232 
Ya a principios del siglo XX, mientras se dejaba atrás el pudor sexual característico de las sociedades occidentales decimonónicas, las fotografías eróticas tuvieron una mayor difusión. En las primeras décadas de este siglo, el desnudo femenino en la fotografía se popularizó por medio de las tarjetas postales. A la vez, se se presentaban al público colecciones de fotografías eróticas en países como Alemania y Reino Unido (Dupouy, 2015). Por su parte, en Estados Unidos, entre las décadas de 1910 y 1940, los fotógrafos -tanto hombres como mujeres- al fotografiar desnudos de mujeres, produjeron un cuerpo femenino exclusivamente heterosexual o "heterosexualizado", lo cual debe entenderse como un cuerpo para consumo masculino; independientemente de la orientación sexual de la modelo (Pultz, 1995).

\section{La fotografía homoerótica}

Ahora, ¿qué hace que una fotografía que presenta al espectador un cuerpo desnudo sea considerada como erótica y no como pornográfica? Si bien en ambas se representa a cuerpos carentes de vestimenta, dentro de una visión conservadora, a la fotografía erótica se le confiere el carácter de "artística" y noble, en oposición a lo degradante de la fotografía pornográfica, que procura provocar excitación en el espectador (Retana, 2008). Esta afirmación está claramente atravesada por un juicio moral que considera la exposición, en primer plano, sin filtros, de la excitación sexual, el coito y el goce del orgasmo como vulgar u obscena.

Lo pornográfico suele estar directamente ligado a lo obsceno, es decir, una violación, o lo que una comunidad en específico puede considerar ofensivo. Sin embargo, no todo lo obsceno es pornográfico: un ejemplo de esto es el caso del gesto con el dedo del centro, considerado obsceno en muchas sociedades, mas no por ello pornográfico. Aun así, la supuesta obscenidad de la pornografía radicaría, como lo indica Michael Rea citando a Elliott, en la representación explícita de actos sexuales que ofenden la decencia, sin ninguna justificación estética (Rea, 2001). En todo caso, la fotografía erótica no se enfoca únicamente en la genitalidad como elemento central de la composición fotográfica, como sí lo hace en la pornografía, lo que hace a esta una de las principales características de la pornografía contemporánea (Retana, 2008).

Históricamente, lo usual es que la fotografía erótica tenga como objeto los desnudos femeninos. Para el siglo XIX, la creencia común era que el cuerpo masculino no debía ser objeto del arte, pues esta debía dirigirse a un público considerado heterosexual (Pultz, 1995). Pese a esto, el cuerpo masculino también fue retratado desde los inicios de la fotografía, aunque no siempre de la misma manera que el femenino. Pultz (1995) menciona el caso de la fotografía tomada por Joseph J. Pennell, en 1905, donde el torso del modelo -un soldado estadounidense blanco de Kansas apellidado Reynolds- está desnudo únicamente 
para mostrar el tatuaje sobre él. El objeto de la fotografía no es el modelo semidesnudo en cuestión, sino su tatuaje y la mirada de este -dirigida directamente a la cámara-. No demuestra ninguna timidez o temor frente al aparato o al fotógrafo. Tanto Pennell como Reynolds se encuentran en una posición activa.

No obstante, en algunos casos, las fotografías de hombres sí estaban dirigidas a un público masculino homosexual ${ }^{4}$. Un claro exponente de la fotografía homoerótica, y excepción para la época, es el fotógrafo alemán Wilhelm von Gloeden, quien retrató a adolescentes sicilianos desnudos a finales del siglo XIX. En su serie de fotografías, los modelos aparecen conscientes de su cuerpo, en poses sensuales o juguetonas, separados entre sí o interactuando entre ellos (Pultz, 1995). Durante esta época, la fotografía homoerótica no se produce únicamente en Europa, sino que también -aunque en menor escala- en países como Estados Unidos, con Thomas Eakins -quien trabaja también la pintura y la esculturao Nueva Zelanda, de la mano de Robert Grant, un británico radicado en la zona, por señalar tan solo dos ejemplos. De ese modo, surge ya en esta época una sensibilidad homoerótica que va creando patrones en las fotografías masculinas, que serán reproducidos en varios países: el erotismo a través de la idea de camaradería, el amigo romántico, el hombre travestido, el marinero, entre otros (Brickwell, 2010).

\section{La mirada gay y el cuerpo masculino}

A la sensación de placer derivada del acto de mirar se la conoce como voyerismo. Freud (1973) la asoció con la acción de tomar a otros como objetos, fuentes de placer, sujetos de una mirada a la vez curiosa y controladora, en la cual, quien mira tiene una posición esencialmente activa. Siguiendo esta misma línea, las concepciones tradicionales de los roles de género han asociado el mirar -activo- con lo masculino, mientras que el ser objeto de dicha mirada -una posición pasiva- con lo femenino. Como consecuencia, el hombre, por lo general, no ha sido sexualmente objetivizado (Mulvey, 1999).

Esta mirada puede ser trasladada a distintos ámbitos, como el del arte, tal y como bien lo señala Laura Mulvey (1999), en su análisis referido al cine. Para la autora, a pesar de que el cine está hecho explícitamente para ser visto y se proyecta en una sala con tal fin, algunas condiciones del entorno en que esto sucede, como el brillo de la pantalla frente a la oscuridad del espacio -que aísla al sujeto y le impide incluso ver a quien está sentado a su lado-, transmiten la sensación de estar mirando el mundo privado de los personajes.

4 Vale la pena señalar que el término "homosexual", como se le conoce hoy en día, no surge sino hasta el siglo XIX, de la mano de las investigaciones en medicina y psicología (Reed, 2011).

ESCENA. Revista de las artes, 2020, Vol. 80, Núm. 1 (julio-diciembre), pp. 223-232 
La mirada del hombre, desde su tradicional posición activa, dicta las formas en que las mujeres han sido representadas en el arte, a lo largo de la historia, desde la pintura, hasta la fotografía o el cine. Es una acción directa sobre el cuerpo de estas: lo moldea, lo modifica, lo contorsiona y lo interpreta a su gusto. Para Mulvey, el acto de mirar no escapa de las dinámicas patriarcales. Al analizar fotografías eróticas en las que se representa a mujeres, se puede extraer más información sobre los miedos y deseos de los hombres, que de las propias mujeres fotografiadas (Christian, 2010).

Empero, ¿qué ocurre cuando es lo masculino quien dirige la mirada, pero, también, es el objeto de esta? Entender la mirada gay en la fotografía homoerótica es entender cómo los hombres homosexuales se han representado a ellos mismos. Ya se mencionó, en la sección anterior, un ejemplo de cómo el cuerpo semidesnudo del hombre fue representado en la fotografía para un público también masculino, pero pensado como heterosexual, sin ningún tipo de intención erótica.

Hablar de una mirada gay -o de cualquier tipo de mirada- es, a su vez, caer en generalizaciones. Sin embargo, es posible extraer algunos puntos en común de trabajos fotográficos elaborados por artistas gays. Steven Drukman, citado por Snider (2008), señala en este aspecto que el espectador gay será inevitablemente universalizado como ejercicio para crear una nueva posición de interpretación, contraria a la tradicional mirada masculina heterosexual.

La mirada gay (gay gaze) también ha sido caracterizada como la manera en que un individuo homosexual identifica a otro por medio de una serie de lenguaje no verbal, como la postura, la vestimenta, el intercambio de miradas, entre otros. A esta práctica se le conoce popularmente con el nombre de "gaydar", una combinación de las palabras "gay" y "radar", en donde tan solo la mirada puede constituir un mensaje de interés recíproco o de identificación como miembro de la comunidad (Nicholas, 2004). Esto se da por medio de marcas que, como lo indica Bourdieu, "reciben su sentido y el valor de su posición en el sistema de signos distintivos que ellas tienden a conformar" (1986, p.185): los hombres homosexuales esperan que sus pares vistan, actúen y se vean de cierta manera, lo cual también es trasladado a la fotografía erótica.

Existe incluso una clasificación de cuerpos en "tribus", término que se ha popularizado en años recientes con la aparición de aplicaciones de citas enfocadas en un público homosexual. Se pertenece a alguna de estas tribus -osos, twinks, nutrias, daddies - con base en atributos meramente físicos. Así, un twink es un chico joven, delgado

${ }^{5}$ Subculturas dentro de la comunidad gay.

ESCENA. Revista de las artes, 2020, Vol. 80, Núm. 1 (julio-diciembre), pp.223-232 
y lampiño, mientras que un oso es un hombre corpulento y generalmente con abundante vello facial. En el caso de estos últimos, la pertenencia a dicho grupo puede darles visibilidad y un sentimiento de comunidad frente al creciente desprecio de los cuerpos más robustos (fat shaming) en comparación con los de otras tribus, en donde su principal característica son los cuerpos delgados o musculosos (Aunspanch, 2015). Existen incluso publicaciones periódicas en donde se presentan fotografías y artículos solamente de sujetos que calzan dentro de alguna de estas tribus, como por ejemplo Bear World Magazine.

Si bien la mirada masculina tradicionalmente objetiviza a la mujer, la mirada gay en la fotografía homoerótica, además de objetivizar al sujeto de la fotografía, provoca también que el observador se identifique con lo que ve. En la fotografía homoerótica, el hombre homosexual es dominante y dominado; tiene una posición tanto activa como pasiva. La construcción de la imagen de hombre homosexual a través de la fotografía resulta altamente valiosa en una sociedad donde las expresiones heterosexuales tienen preeminencia (Leraton, 2002), mientras que las categorizadas como de los otros -en este caso, los homosexuales- son marginalizadas, atacadas y condenadas a la clandestinidad o a espacios underground (clubes, bares, saunas, entre otros).

Los gustos personales por las distintas características corporales son tan diversos como los cuerpos mismos, pero aun así se pueden mencionar una serie de generalidades que diferencian a la fotografía erótica que presenta mujeres desnudas de la homoerótica. En primer lugar, el cuerpo masculino homosexual, y lo que debe o no gustar a los gays, en efecto, está igualmente atravesado por, y es producto de, configuraciones sociales y culturales, que a su vez moldean los gustos (Bourdieu, 1986). Por ejemplo, en las revistas de moda o eróticas dedicadas a un público gay, los tonos de piel más claro y los cuerpos trabajados en gimnasios siguen siendo predominantes. Mientras que hombres considerados más afeminados o con cuerpos no hegemónicos, por lo general, no tienen cabida en este tipo de publicaciones (Christian, 2010).

En segundo lugar, en estas fotografías surgen o se trasladan zonas erógenas usualmente atractivas para el espectador gay: brazos levantados para mostrar axilas, modelos con músculos bastante trabajados -frente a la delicadeza de las curvas de las modelos femeninas retratadas- $y$, en algunas fotografías, vello corporal en piernas, torso y pubis, contrario a los cuerpos "lisos" de las mujeres. En muchos casos, las imágenes de los cuerpos masculinos son mostradas de manera fragmentada, haciendo énfasis únicamente en la zona erógena deseada: fotografías enfocando la zona de la entrepierna o torsos esculturales sin cabeza, no identificables son tan comunes como las que muestras una imagen completa del sujeto (Christian, 2010). 
Como último punto, es importante señalar que el homoerotismo también ha sido utilizado por compañías de moda para posicionar sus productos en el mercado, dado que se muestran cuerpos masculinos vestidos con prendas que se pretenden vender a otros hombres. Un ejemplo de esto es la promoción de la colección de otoño-invierno de Gucci en 2001, del polémico fotógrafo Terry Richardson, en donde un joven toma firmemente su cinturón con su mano izquierda, en alusión a un falo. Dolce \& Gabanna y Calvin Klein han producido material similar, en el que se utilizan modelos masculinos, por lo general musculosos y lampiños, con o sin camisa, interactuando erótica o románticamente entre ellos -como la imagen de dos jóvenes a punto de darse un beso para la colección de jeans de Calvin Klein, en 2015-.

\section{Conclusiones}

Quien toma u observa una fotografía, por lo general, estará en una posición de poder frente a quien es retratado, pues este cumple un rol pasivo frente a la mirada del espectador. Las miradas masculinas tanto heterosexuales como homosexuales moldean y tienen una injerencia directa en los cuerpos de quienes son retratados, ya sean hombres o mujeres. La principal diferencia radica en que, en la mirada gay, quien observa puede llegar a identificarse con quien es fotografiado.

En la fotografía homoerótica, el cuerpo masculino ha sido representado travestido, como amigo romántico, completo o fragmentado, musculoso, sin imperfecciones, delgado, depilado o con vello, viril. De cualquiera de estas maneras, al coincidir el sujeto con el objeto -ambos hombres homosexuales- la persona retratada no solo es objeto de deseo, sino también fin o aspiración idealizada de quien observa. Esta identificación entre ambas partes no ocurre cuando un hombre heterosexual observa fotografías de mujeres desnudas, ya sean consideradas eróticas o pornográficas.

\section{Referencias:}

Agamben, G. (2011). Desnudez. Barcelona: Editorial Anagrama.

Aunspanch, C. (2015). From the Gay Bar to the Search Bar: Promiscuity, Identity and Queer Movility on Grindr (Tesis para obtener el grado de Maestría). University of $\mathrm{Ne}$ braska, Nebraska, Estados Unidos.

Bourdieu, P. (1986). Notas provisionales sobre la percepción social del cuerpo. En F. Álvarez y J. Varela (Eds), Materiales de sociología crítica (pp.183-194). Madrid: La Piqueta.

Brickwell, C. (2010). Visualizing Homoerotism: The Photographs of Robert Gant, 18871892. Visual Anthropology, 23, 136-157.

ESCENA. Revista de las artes, 2020, Vol. 80, Núm. 1 (julio-diciembre), pp.223-232 
Christian, A. (2010). Are We Killing the Boys Harshly? The Consuption of The Male Gaze in Queer Pages (Tesis para obtener el grado de Maestría). Indiana University, Indiana, Estados Unidos.

Clark, K. (1984). El desnudo: un estudio de la forma ideal. Madrid: Alianza Editorial.

Dupouy, A. (2015). Erotic Photography. New York: Parkstone International.

Freud, S. (1973). Tres ensayos sobre teoría sexual. Madrid: Alianza Editorial.

Leraton, R. (2002). Le film porno gay: Histoire, représentations et construction d'une sexualité. Montblanc: H\&O Éditions.

Mulvey, L. (1999). Visual Pleasure and Narrative Cinema. En L. Braudy y M. Cohen (Eds), Film Theory and Criticism: Introductory Readings (pp. 833-844). Nueva York: Oxford UP.

Nicholas, C. (2004). Gaydar: Eye-Gaze as Identity Recognition Among Gay Men and Lesbians. Sexuality and Culture, 8, 60-86.

Pultz, J. (1995). The Body and the Lens: Photography 1839 to the Present. Nueva York: Harry N. Abrams Inc. Publishers.

Rea, M. (2001). What Is Pornography?. Nous, 35, 118-145.

Reed, C. (2011). Art and Homosexuality. Oxford: University Press.

Retana, C. (2008). Pornografía: la tiranía de la mirada. San José: Editorial Arlekín.

Sontag, S. (2007). Sobre la fotografía. Madrid: Editorial Alfaguara.

Snider, C. (2008). Queer Persona and the Gay Gaze in Brokeback Mountain: Story and Film. Psychological Perspectives, 51, 54-69. 